\title{
Large-Scale Fabrication of RF MOSFETs on Liquid-Exfoliated $\mathrm{MoS}_{2}$
}

\author{
Kuanchen Xiong ${ }^{\# 1}$, Lei Li ${ }^{\#}$, Asher Madjar", James C. M. Hwang\#, Zhaoyang Lin*, Yu Huang*, Xiangfeng Duan*, \\ Alexander Göritz ${ }^{+}$, Matthias Wietstruck ${ }^{+}$, and Mehmet Kaynak ${ }^{+}$ \\ "Lehigh University, Bethlehem, Pennsylvania 18015 USA \\ *University of California, Los Angeles, California 90095 USA \\ +IHP, Im Technologiepark 25, 15236 Frankfurt (Oder), Germany \\ ${ }^{1}$ kux214@lehigh.edu
}

\begin{abstract}
For the first time, thousands of RF MOSFETs were batch-fabricated on liquid-exfoliated $\mathrm{MoS}_{2}$ below $300{ }^{\circ} \mathrm{C}$ with nearly $100 \%$ yield. The large-scale fabrication with high yield allowed the average performance instead of the best performance to be reported. The DC performance of these devices were typical, but the RF performance, enabled by buried gates and on the order of $100 \mathrm{MHz}$, was reported for the first time for liquid-exfoliated $\mathrm{MoS}_{2}$. To resolve the dilemma of thin vs. thick films, gate recess was used on 20-nm thick films to improve the gate control while keeping the contact resistance lower than that on $10-\mathrm{nm}$ films. These innovations may enable thin-film transistors to operate in the microwave range.
\end{abstract}

Index Terms - Electrochemical process, CMOS process, MOSFET, semiconductor device manufacture, semiconductor nanostructures, thin film transistors, wafer scale integration.

\section{INTRODUCTION}

Two-dimensional atomic-layered materials such as $2 \mathrm{H}-\mathrm{MoS}_{2}$ have high charge carrier mobility without epitaxy requirement. They are therefore promising materials for thin-film transistors to operate in the microwave range, well beyond that of currentgeneration $\mathrm{InGaZnO}$ devices. To date, most $\mathrm{MoS}_{2}$ transistors have been individually crafted by direct-write electron-beam lithography on micrometer-size flakes mechanically exfoliated from bulk crystals. Recently, scores of MOSFETs and smallscale integrated circuits were fabricated on large-area $\mathrm{MoS}_{2}$ synthesized by chemical vapor deposition [2]. However, the process required a thermal budget on the order of $1000{ }^{\circ} \mathrm{C}$, which is incompatible with typical thin-film processes.

Table 1. MOSFETs Fabricated on Liquid-Exfoliated $\mathrm{MoS}_{2}$

\begin{tabular}{|c|c|c|c|c|c|c|c|c|c|}
\hline \multirow[b]{2}{*}{ Year } & \multicolumn{2}{|c|}{$\mathrm{MoS}_{2}$ Flake } & \multicolumn{2}{|c|}{ FET Channel } & \multirow[b]{2}{*}{$\begin{array}{c}\text { Cover- } \\
\text { age }\end{array}$} & \multirow[b]{2}{*}{ Gate } & \multirow{2}{*}{$\begin{array}{c}\text { Mobil- } \\
\text { ity } \\
\mathrm{cm}^{2} / \mathrm{Vs}\end{array}$} & \multirow[b]{2}{*}{$\begin{array}{l}\text { On/Off } \\
\text { Ratio }\end{array}$} & \multirow[b]{2}{*}{ Ref. } \\
\hline & $\begin{array}{c}\text { Thick. } \\
\mathrm{nm}\end{array}$ & $\begin{array}{c}\text { Length } \\
\mu \mathrm{m}\end{array}$ & \begin{tabular}{|c} 
Thick. \\
nm
\end{tabular} & $\begin{array}{c}\text { Length } \\
\mu \mathrm{m}\end{array}$ & & & & & \\
\hline 2011 & 10 & 1 & 100 & 1 & Low & Subs. & 0.1 & 10 & [3] \\
\hline 2011 & 1 & 1 & 1 & 1 & Low & Subs. & \begin{tabular}{|l|}
0.001 \\
\end{tabular} & --- & [4] \\
\hline 2013 & 10 & 10 & 10 & 1 & Low & Ion & 1 & 100 & [5] \\
\hline 2014 & 1 & 10 & 1 & 10 & Low & Subs. & 1 & $10^{6}$ & [6] \\
\hline 2014 & 10 & 0.1 & 100 & 10 & High & Subs. & $10^{-5}$ & 10 & [7] \\
\hline 2017 & 10 & 1 & 1000 & 100 & High & Ion & 0.1 & 100 & [8] \\
\hline $\begin{array}{l}\text { Pre- } \\
\text { sent }\end{array}$ & 10 & 1 & 10 & 1 & High & Buried & 0.01 & 10 & $\begin{array}{c}\text { This } \\
\text { Work }\end{array}$ \\
\hline
\end{tabular}

By contrast, liquid-exfoliated and dispensed $\mathrm{MoS}_{2}$ can be applied near room temperature, in large area, and at low cost, making it attractive for thin-film processes. Over the past decade, there have been many attempts to demonstrate MOSFETs on liquid-exfoliated $\mathrm{MoS}_{2}$ as listed in Table 1. However, they typically exhibited either high performance on thin film with low coverage, or low performance on thick film with high coverage. Additionally, they used either the entire substrate or an ion liquid as the gate electrode, rendering them inoperable at radio frequencies. To resolve the dilemma of thin vs. thick films, we recessed the gate following the established practice on compound semiconductors [9] and recent attempts on black phosphorous [10], [11]. To enable RF operation, we fabricated submicron buried gates with low parasitic inductance and capacitance. These innovations are described in the following.

\section{DEVICE FABRICATION}

Thousands of $\mathrm{MoS}_{2}$ MOSFETs were batch-processed through three major steps: (A) formation of buried gates, (B) spin-coating of $\mathrm{MoS}_{2}$, and (C) definition of active and contact regions. To facilitate the gate-recess experiment, although step A was carried out on a $200-\mathrm{mm}$ Si wafer, the wafer was subsequently diced into $25 \mathrm{~mm} \times 15 \mathrm{~mm}$ chips before steps $\mathrm{B}$ and $\mathrm{C}$.

A one-mask photolithography process was used to form $\mathrm{Al}$ gates buried in $\mathrm{SiO}_{2}$, before deposition of gate oxide and $\mathrm{MoS}_{2}$ (Fig. 1). This way, gate oxide could be deposited at relatively high temperature without damaging $\mathrm{MoS}_{2}$. To this end, stateof-the-art CMOS processes are capable of not only submicron gate and high-quality gate oxide, but also flat surface through chemo-mechanical polishing to ensure smooth dispense of $\mathrm{MoS}_{2}$. Specifically, the back-end-of-line process of the SG13S foundry process by IHP Microelectronics with a thermal budget of $450{ }^{\circ} \mathrm{C}$ was chosen. Using a $200-\mathrm{mm}$ high-resistivity $(10$ $\mathrm{k} \Omega \cdot \mathrm{cm}$ ) Si wafer, approximately sixty $25 \mathrm{~mm} \times 15 \mathrm{~mm}$ chips were fabricated, with each chip containing approximately 1500 RF-probable MOSFETs. Each MOSFET has two buried gates with a total gate width of approximately $10 \mu \mathrm{m}$. The sourcegate spacing, gate length, and gate-drain spacing were approximately $0.4 \mu \mathrm{m}, 0.6 \mu \mathrm{m}$, and $0.4 \mu \mathrm{m}$, respectively. The gate 


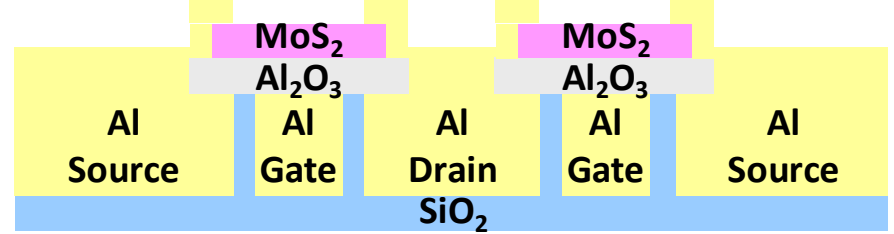

(a)

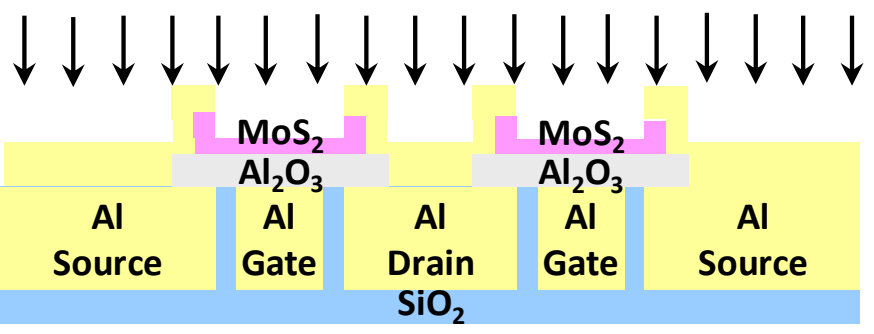

(b)

Fig. 1. Cross-section schematic (not to scale) of a $\mathrm{MoS}_{2}$ MOSFET (a) before and (b) after gate recess.

thickness was approximately $0.5 \mu \mathrm{m}$. Following chemo-mechanical polishing, $\mathrm{Al}_{2} \mathrm{O}_{3}$ gate oxide approximately $30-\mathrm{nm}$ thick was deposited by atomic layer deposition (ALD) at 250 ${ }^{\circ} \mathrm{C}$. Fig. 2(a) shows a MOSFET at this process step.

The isopropanol suspension of $\mathrm{MoS}_{2}$ contained flakes with a thickness of 3-6 nm and a lateral size of 1-2 $\mu \mathrm{m}$. The suspension was spun onto the chips of step A at $2000 \mathrm{rpm}$ for $20 \mathrm{~s}$, followed by annealing at $300{ }^{\circ} \mathrm{C}$ for $1 \mathrm{~h}$ in argon. The spincoating process was repeated two and four times to obtain $\mathrm{MoS}_{2}$ films with approximately 10- and 20-nm thicknesses, respectively, as confirmed by atomic force microscopy. The atomic force microscopy confirmed also that the films were continuous despite a roughness of approximately $5 \mathrm{~nm}$, which resulted in grainy contrast under the optical microscope as shown in Fig. 2(b). The chip coated with $10-\mathrm{nm} \mathrm{MoS}_{2}$ served as a control; the chip coated with 20-nm $\mathrm{MoS}_{2}$ would undergo gate recessing.

A two-mask photolithography process was used to define the active and contact regions of all 1500 MOSFETs on each chip. To define the active region, $\mathrm{MoS}_{2}$ was dry-etched by $\mathrm{CHF}_{3} / \mathrm{O}_{2}$ whereas $\mathrm{Al}_{2} \mathrm{O}_{3}$ was wet-etched by buffered HF. Source and drain contacts were formed by electron-gun evaporated $\mathrm{Ti}$ and Al with thicknesses of $10 \mathrm{~nm}$ and $490 \mathrm{~nm}$, respectively. Gate recessing was performed by dry etching with $\mathrm{CHF}_{3} / \mathrm{O}_{2}$ for $50 \mathrm{~s}$ using the source and drain contacts as self-aligned masks.

\section{RESULT AND DisCUSSION}

Random sampling confirmed that, before gate recessing, nearly all 1500 MOSFETs fabricated on each chip had sourcedrain conduction, whether the chip was coated with $10-\mathrm{nm}$ or 20-nm $\mathrm{MoS}_{2}$. However, whereas devices on 10-nm $\mathrm{MoS}_{2}$ exhibited effective gate control, devices on 20-nm $\mathrm{MoS}_{2}$ exhibited no gate modulation up to a gate-source voltage of $10 \mathrm{~V}$, presumably because the channel was too thick. Correspondingly, the total source-drain resistance was reduced from $28 \pm 8$

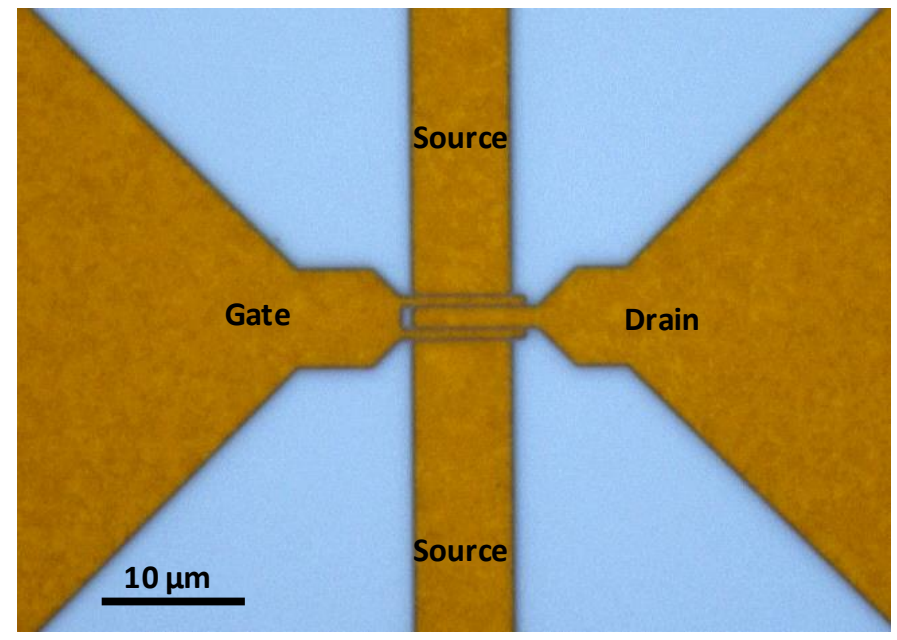

(a)

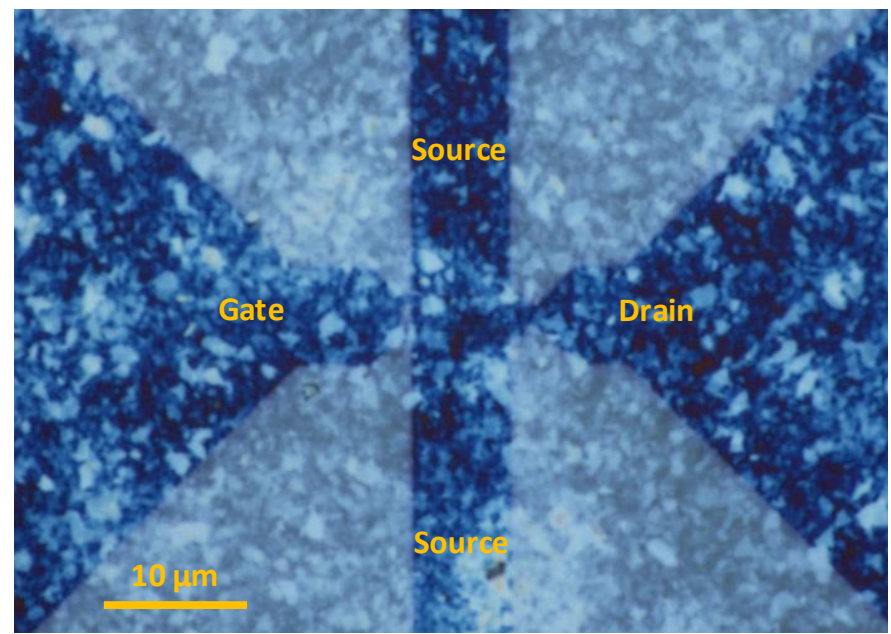

(b)

Fig. 2. Micrographs of a MOSFET (a) before and (a) after spin-coating of 10-nm-thick $\mathrm{MoS}_{2}$

$\mathrm{M} \Omega \cdot \mu \mathrm{m}$ for devices on $10-\mathrm{nm} \mathrm{MoS}$ to $20 \pm 10 \mathrm{M} \Omega \cdot \mu \mathrm{m}$ for devices on $20-\mathrm{nm} \mathrm{MoS}$. (The reduction is less than $50 \%$ because the source-drain resistance is presently dominated by the contact resistance.) Devices on 20-nm $\mathrm{MoS}_{2}$ exhibited effective gate control only with gate recess. However, the gate was overrecessed and only 90 of the 1500 devices survived, with the yield dropping from $100 \%$ to approximately $6 \%$. Visual inspection confirmed that only 167 devices had channel material left after gate recessing. Thus, although the present experiment demonstrated the benefit of gate recessing in improving gate control and reducing contact resistance, much process development and control are needed. For example, gate recessing could be done with wet etching instead of dry etching to avoid damaging the channel material. Historically, gate recessing has been the most critical process step for compound semiconductor devices [9].

For the chip coated with 10-nm $\mathrm{MoS}_{2}$, Fig. 3(a) shows the transfer characteristics of a typical MOSFET. The drain current 


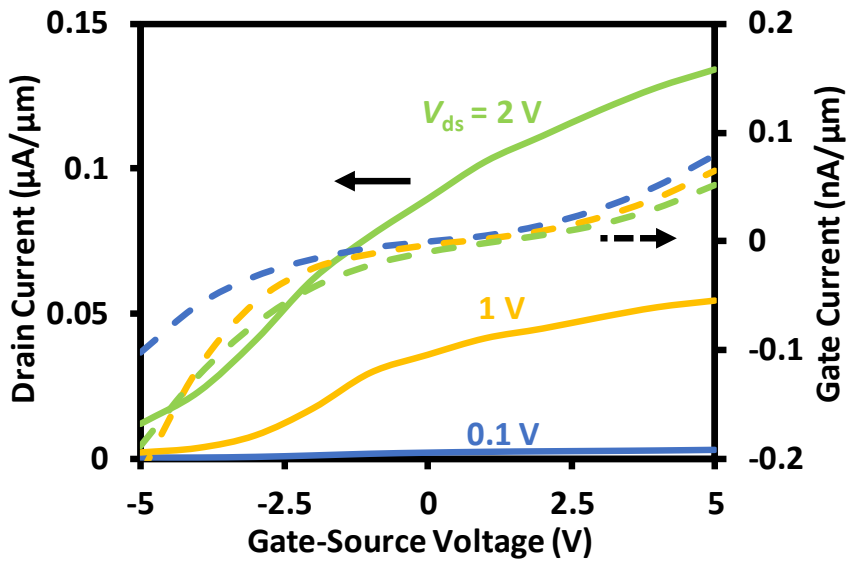

(a)

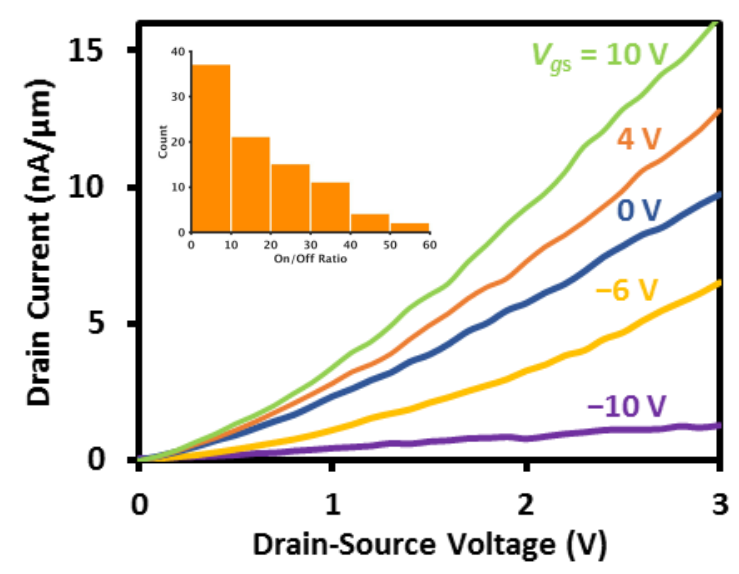

(b)

Fig. 3. (a) Transfer characteristics of a typical MOSFET fabricated on 10$\mathrm{nm} \mathrm{MoS}$ without gate recess, and (b) drain characteristics of a typical MOSFET fabricated on 20-nm $\mathrm{MoS}_{2}$ with gate recess. Inset in (b) shows histograhm of on/off current ratio.

of approximately $0.15 \mu \mathrm{A} / \mu \mathrm{m}$, the field-effect mobility of approximately $0.03 \mathrm{~cm}^{2} / \mathrm{Vs}$, and the on/off current ratio of approximately 12 are typical of MOSFETs fabricated on liquid-exfoliated $\mathrm{MoS}_{2}$ as listed in Table I. (The field-effect electron mobility $\mu_{F E}$ is calculated according to $\mu_{F E}=g_{M} L / C_{O X} V_{D S} W$, where $g_{M}$ is the peak transconductance, $L$ and $W$ are the channel length and width, respectively, $C_{O X}$ is the oxide capacitance, and $V_{D S}$ is the drain-source voltage.) However, the de-embedded (from large probe pad capacitances [12]) forward-current cutoff frequency $f_{T}$ of approximately $38 \mathrm{MHz}$ and the maximum oscillation frequency of $f_{M A X}$ of approximately $49 \mathrm{MHz}$ (Fig. 4) are the first time to be reported for any MOSFET fabricated on liquidexfoliated $\mathrm{MoS}_{2}$. Although the $f_{T}$ and $f_{M A X}$ are far from the microwave range, they are already comparable or better than that of current-generation $\mathrm{InGaZnO}$ devices. Detailed analysis showed that presently $f_{T}$ and $f_{M A X}$ are mainly limited by large parasitic resistances associated with both the source contacts and the source-gate access region. These parasitic resistances also prevented the drain current from saturating below $3 \mathrm{~V}$. These parasitic resistances may be reduced by a shorter source-

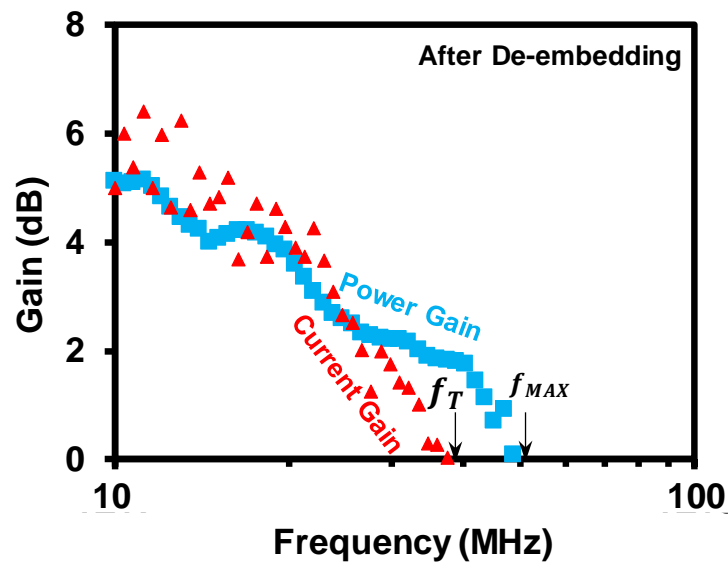

Fig. 4. De-embedded forward current gain cutoff frequency $f_{T}$ and maximum frequency of oscillation $f_{M A X}$ of a typical MOSFET fabricated on 10-nm liquid-exforliated $\mathrm{MoS}_{2}$.

gate distance and a more optimum gate-recess profile. Nevertheless, Fig. 3(a) shows also that the gate leakage current is less than $1 \mathrm{nA} / \mu \mathrm{m}$, which attests to the high-quality gate oxide afforded by the buried-gate configuration.

For the chip coated with 20-nm $\mathrm{MoS}_{2}$, Fig. 3(b) shows that gate recess improves the on/off current ratio, but reduces the current capacity, presumably due to damage by dry etching. The inset shows that the on/off ratio of the 90 surviving devices is $18 \pm 12$ with the maximum being 60 . Correspondingly, the threshold is $-9 \mathrm{~V} \pm 6 \mathrm{~V}$. The present large-scale fabrication allows average characteristics to be reported, whereas others in Table I report best characteristics.

\section{CONCLUSION}

For the first time, thousands of RF MOSFETs were batchfabricated on liquid-exfoliated $\mathrm{MoS}_{2}$ with nearly $100 \%$ yield. The large-scale fabrication allowed the average performance instead of the best performance to be reported. The DC performance of these devices were typical of that of MOSFETs fabricated on liquid-exfoliated $\mathrm{MoS}_{2}$, with drain current $\sim 0.1$ $\mu \mathrm{A} / \mu \mathrm{m}$, electron mobility $\sim 0.01 \mathrm{~cm}^{2} / \mathrm{Vs}$, and on/off ratio $\sim 10$. However, the RF performance, on the order of $100 \mathrm{MHz}$, was reported for the first time. The RF performance was enabled by buried gates with low parasitic inductance and capacitance. Additionally, to resolve the dilemma of thin vs. thick films, gate recess was introduced to $\mathrm{MoS}_{2}$ MOSFETs for the first time, which improved gate control and contact resistance. However, the present process is far from optimum for achieving the full potential of the material, which had been shown to result in orders-of-magnitude higher mobility and on/off ratio with a substrate gate. Therefore, with further process development and optimization, especially in reducing the parasitic resistances of the source contact and the source-gate access region, these innovations and results suggest that $\mathrm{MoS}_{2}$ MOSFETs may enable thin-film transistors to operate in the microwave range. 


\section{ACKNOWLEDGMENT}

This work was supported in part by the U.S. Office of Naval Research under Grant N00014-14-1-0653, the Air Force Office of Scientific Research and the National Science Foundation (NSF) under EFRI 2-DARE Grant 1433541 and Grant 1433459. This work was performed in part at the Cornell NanoScale Facility, a member of the National Nanotechnology Coordinated Infrastructure, which is supported by NSF under Grant ECCS-1542081.

\section{REFERENCES}

[1] Z. Lin, A. McCreary, N. Briggs, S. Subramanian, K. Zhang, Y. Sun, X. Li, N. J. Borys, H. Yuan, S. K. Fullerton-Shirey, A. Chernikov, H. Zhao1, S. McDonnell, A. M. Lindenberg, K. Xiao, B. J. LeRoy, M. Drndic, J. C. M. Hwang, J. Park, M. Chhowalla, R. E. Schaak, A. Javey, M. C. Hersam, J. Robinson, and M. Terrones, "2D materials advances: From large scale synthesis and controlled heterostructures to improved characterization techniques, defects and applications," 2 D Mater., vol. 3, no. 4, pp. 420011-42001-38, Dec. 2016.

[2] S. Wachter, D. K. Polyushkin, O. Bethge, and T. Mueller "A microprocessor based on a two-dimensional semiconductor," Nat. Commun., vol. 8, no. 1, pp. 14948-1-14948-1, Apr. 2017.

[3] K. Lee, H.-Y. Kim, M. Lotya, J. N. Coleman, G.-T. Kim, and G. S. Duesberg, "Electrical characteristics of molybdenum disulfide flakes produced by liquid exfoliation," Adv. Mater. (Weinheim, Ger.), vol. 23, no. 36, pp. 4178-4182, Sep. 2011.

[4] Z. Zeng, Z. Yin, X. Huang, H. Li, Q. He, G. Lu, F. Boey, and H. Zhang "Single-layer semiconducting nanosheets: High-yield preparation and device fabrication," Angew. Chem., Int. Ed., vol. 50, no. 47, pp. 11093 11097, Nov. 2011

[5] V. Pachauri, K. Kern, and K. Balasubramanian, "Chemically exfoliated large-area two-dimensional flakes of molybdenum disulfide for device applications," APL Mater., vol. 1, no. 3, pp. 032102-1-032102-9, Sep. 2013.

[6] N. Liu, P. Kim, J. H. Kim, J. H. Ye, S. Kim, and C. J. Lee, "Large-area atomically thin MoS2 nanosheets prepared using electrochemical exfoliation," ACS Nano, vol. 8, no. 7, pp. 6902-6910, Jul. 2014.

[7] J. Li, M. M. Naiin, S. Vaziri, M. C. Lemme, and M. Östling, "Inkjet printing of $\mathrm{MoS}_{2}$, , Adv. Funct. Mater., vol. 24, no. 41, pp. 6524-6531, Nov. 2014.

[8] A. G. Kelly, T. Hallam, C. Backes, A. Harvey, A. S. Esmaeily, I. Godwin, J. Coelho, V. Nicolosi, J. Lauth, A. Kulkarni, S. Kinge, L. D. A. Siebbeles, G. S. Duesberg, and J. N. Coleman, "All-printed thin-film transistors from networks of liquid-exfoliated nanosheets," Science, vol. 356, no. 6333, pp. 69-73, Apr. 2017.

[9] W. C. Niehaus, S. H. Wemple, H. M. Cox, L. A. D'Asaro, J. V. DiLorenzo, H. Fukui, J. C. M. Hwang, J. C. Irvin, and W. O. Schlosser, "GaAs power FETs device principles, fabrication processes and material technology," in GaAs FET Principles Technology, J. V. DiLorenzo, and D. D. Khandelwal, Ed. Dehdam, MA: Artech House, 1982, pp. 279-306.

[10] J. Jia, S. K. Jang, S. Lai, J. Xu, Y. J. Choi, J. H. Park, and S. Lee, "Plasmatreated thickness-controlled two-dimensional black phosphorus and its electronic transport properties," ACS Nano, vol. 9, no. 9, pp. 8729-8736, Sep. 2015.

[11] X. Liu, K. S. Chen, S. A. Wells, I. Balla, J. Zhu, J. D. Wood, and M. C. Hersam, "Scanning probe nanopatterning and layer-by-layer thinning of black phosphorus," Adv. Mater., vol. 29, no. 1, pp. 1604121-1-16041217, Jan. 2017.

[12] G. Dambrine, A. Cappy, F. Heliodore, and E. Playez, "A new method for determining the FET small-signal equivalent circuit," IEEE Trans. Microwave Theory Tech., vol. 36, no. 7, pp. 1151-1159, Jul. 1988. 